Gut, 1968, 9, 489-493

\title{
Acute fatty liver of pregnancy
}

\author{
R. A. JOSKE, D. J. McCUlly, AND F. L. MASTAGlia \\ From the Departments of Medicine and Pathology, \\ University of Western Australia
}

Acute fatty liver of pregnancy was established as an entity by Sheehan (1940) under the name 'obstetric acute yellow atrophy'. He reviewed the earlier literature and distinguished three types of acute hepatic failure in pregnancy.

The first of these was 'true acute yellow atrophy', and corresponds to the disease now called massive hepatic necrosis. It may occur in pregnant or nonpregnant patients, and is characterized pathologically by massive parenchymal cell necrosis without fatty change in liver cells. It is generally ascribed, although without proof, to a fulminating acute virus hepatitis.

Sheehan's second entity was delayed chloroform poisoning. The pathological change in this was of liver cell necrosis occurring in isolated cells, or as mid-zonal or centrilobular necrosis. Affected cells had a swollen, non-fatty cytoplasm and pyknotic nucleus, and fatty change was slight or absent. However, this lesion is now of historic rather than clinical interest.

The third type of liver change Sheehan termed 'obstetric acute yellow atrophy'. This was clinically similar to massive hepatic necrosis but occurred only late in pregnancy at 36 to 40 weeks and was frequently associated with toxaemic manifestations such as hypertension and proteinuria. It progressed rapidly, leading to maternal death within two weeks. The histological appearances were characteristic. There was 'an entire absence of necrobiosis', but an intense fatty change affecting all cells of the lobule, except for a sharply defined rim of normal cells adjacent to the portal tracts. This fatty change occurred diffusely thoughout the cytoplasm, giving it a ballooned, vacuolated appearance. The distribution of the affected cells and the diffuse fatty change throughout the cytoplasm clearly distinguished the condition from the occasional fat droplets seen in centrilobular cells following hyperemesis of late pregnancy (Sheehan, 1939). Portal tracts were normal and bile thrombi rare or absent. This obstetric acute yellow atrophy is now generally called acute fatty liver of pregnancy. It remains probably the gravest form of liver disease in pregnancy.
In recent years, some authors have included fatty liver associated with tetracycline therapy during pregnancy in the general group of acute fatty liver of pregnancy (Kunelis, Peters, and Edmondson, 1965). It does, however, occur in non-pregnant patients, and may be associated with other drugs of the tetracycline series (Saint and Joske, 1953; Klatskin, 1963). Despite its clinical and pathological similarities to acute fatty liver of pregnancy, it should, therefore, be regarded as a separate entity with a different aetiology and pathogenesis.

True acute fatty liver of pregnancy is a rare condition. Ober and LeCompte (1955) reported 14 cases including three of their own in 1955, and in 1966 Haemmerli extended the collective experience to 40 cases. The clinical picture is of a rapidly progressive parenchymal cell failure which is clinically indistinguishable from that of acute massive necrosis. It has been reported in patients ranging in age from 16 to 42 years, and in 37 of the 40 cases it occurred during the first pregnancy. The prognosis is grave: of the 40 cases collected by Haemmerli, only six mothers and five children have survived.

The pathological appearances in all cases correspond to those described by Sheehan (1940). They are potentially reversible, for in one survivor followed up by serial liver biopsies, normal histological appearances were ultimately restored (Whitacre and Fang, 1942).

The present paper reports a further case of acute fatty liver of pregnancy, which is of interest because of some unusual features, in particular steady progression of the lesion despite delivery of a living child, haemolytic anaemia, and the finding at necropsy of massive mid-zonal hepatic necrosis.

\section{CASE REPORT}

A primipara aged 21 years had a normal pregnancy until the thirty-seventh week, when she developed oedema of both legs to the knees and was noted by her husband to be jaundiced. There was no history of jaundice or of exposure to hepatitis or hepatotoxic drugs or chemicals. Two days later (day 3) she was admitted to hospital, where she was found to have a blood pressure of 150/ $100 \mathrm{~mm} \mathrm{Hg}$ (previously $135 / 50 \mathrm{~mm} \mathrm{Hg}$ ), and protein- 
TABLE I

SUMMARY OF LABORATORY DATA

\begin{tabular}{|c|c|c|c|c|}
\hline Investigation & Day 7 & Day 9 & Day 11 & Day 12 \\
\hline Haemoglobin $(\mathrm{g} / 100 \mathrm{ml})$ & $12 \cdot 6$ & $9 \cdot 2$ & $9 \cdot 9$ & $14 \cdot 2$ \\
\hline Haematocrit $(\%)$ & & 29 & 31 & 42 \\
\hline Reticulocyte count (per 100 red cells) & & 10 & $7 \cdot 0$ & - \\
\hline Nucleated red cells (per 100 red cells) & & 12 & 49 & 35 \\
\hline White blood cell count (per cu mm) & & 21,000 & 20,000 & 27,000 \\
\hline \multicolumn{5}{|l|}{ Differential count $(\%)$} \\
\hline Neutrophils & & 82 & 85 & 74 \\
\hline Lymphocytes & & 10 & 9 & 10 \\
\hline Monocytes & & 5 & - & 4 \\
\hline Eosinophils & & - & 2 & - \\
\hline Metamyelocytes & & 3 & 4 & 8 \\
\hline Myelocytes & & - & - & 4 \\
\hline Platelet count (per cu mm) & & 62,000 & 57,000 & 42,000 \\
\hline Serum haptoglobins $(\mathrm{mg} / 100 \mathrm{ml})$ & & $<10$ & - & $<10$ \\
\hline Serum bilirubin $(\mathrm{mg} / 100 \mathrm{ml})$ & $12 \cdot 0$ & 20 & 21 & 31 \\
\hline $\begin{array}{l}\text { Serum alkaline phosphatase } \\
\text { (King-Armstrong units) }\end{array}$ & & 26 & 22 & 22 \\
\hline Serum glutamic pyruvic transaminase (Karmen units) & 69 & 51 & 48 & - \\
\hline Blood ammonia nitrogen $(\mu \mathrm{g} / 100 \mathrm{ml})$ & & 264 & 405 & 450 \\
\hline Plasma urea $(\mathrm{mg} / 100 \mathrm{ml})$ & & 155 & 110 & 116 \\
\hline Serum protein electrophoresis (grams $/ 100 \mathrm{ml}$ ) Albumin & & $1 \cdot 87$ & - & - \\
\hline al-Globulin & & 0.34 & - & - \\
\hline a2-Globulin & & 0.78 & - & - \\
\hline$\beta$-Globulin & & 0.43 & - & - \\
\hline$\gamma$-Globulin & & 0.78 & - & - \\
\hline Thymol turbidity & & - & 0 & 2 \\
\hline \multicolumn{5}{|l|}{ Plasma electrolytes (m-equiv/1) } \\
\hline Sodium & 122 & 141 & 143 & 152 \\
\hline Potassium & 4.1 & 3.7 & $3 \cdot 9$ & $4 \cdot 7$ \\
\hline Bicarbonate & 31 & 20 & 25 & 18 \\
\hline Chloride & 99 & - & 106 & 102 \\
\hline
\end{tabular}

uria. She was treated with bed rest and chlorothiazide $500 \mathrm{mg}$ daily, and on day 6 was delivered of a normal male infant. Labour was spontaneous and delivery uncomplicated until 11 hours after delivery when she sustained a haemorrhage of $600 \mathrm{ml}$ per vaginam and vomited altered blood. Her systolic blood pressure fell to $40 \mathrm{~mm} \mathrm{Hg}$ and she received 2 pints of plasma and 1 of blood over the next four hours, with restoration of her blood pressure. The intravenous infusion was then continued with dextrose and saline solutions, 2 litres daily. Her condition showed little change and on day 9 the serum bilirubin level was $12 \mathrm{mg} \%$.

She was admitted to the Royal Perth Hospital on day 9. At this time, she was disorientated in time and place. Pulse was 120 per minute and blood pressure $140 / 85 \mathrm{~mm} \mathrm{Hg}$. There was moderate jaundice and pitting oedema of all extremities. The cervical venous pressure was not raised, and the heart and chest showed no abnormal signs. Neither liver nor spleen was palpable. Neurological examination showed that the limbs were hypotonic with some muscular twitching. The reflexes were symmetrical and brisk and the plantar responses flexor. The genitalia showed the usual signs of a recent delivery. There were no signs of chronic liver disease such as spider naevi or palmar erythema.

Serial haematological studies and liver function tests are shown in Table I. A chest radiograph and vaginal swab were normal. The urine contained protein and culture grew coliform organisms. The blood film showed anisocytosis, burr cells, and fragmented cells, with normoblasts and occasional macronormoblasts with
Howell-Jolly bodies; there was toxic granulation of neutrophils. Direct and indirect Coombs tests were negative. Blood cultures and a cervical smear grew no pathogens.

Treatment was begun with kanamycin $3.0 \mathrm{~g}$ daily and ampicillin $2.0 \mathrm{~g}$ daily by intragastric tube and methicillin $4.0 \mathrm{~g}$ daily by injection. A transfusion of 1 pint of blood was given followed by dextrose and saline solution. On day 10 she was stuporose, with neck retraction, hypertonia, and augmented tendon reflexes. Spider naevi appeared over the arms and chest. The liver remained impalpable. The following day she developed clonic movements of the limbs which were controlled only by the use of phenobarbital, paraldehyde, and magnesium sulphate by injection. Hydrocortisone was also given by injection, $400 \mathrm{mg}$ daily. Other treatment, including further blood transfusion, was contined.

Her progress was steadily downhill and chest infection required tracheostomy on day 12 . Her urinary output was maintained and exceeded $1,800 \mathrm{ml}$ daily. The blood ammonia nitrogen level continued to rise, and she developed hyperpyrexia $\left(40 \cdot 5^{\circ} \mathrm{C}\right)$ and died on the following day.

Necropsy was performed nine-and-a-half hours after death. The body was that of a well-nourished, deeply jaundiced, young female (weighing $49 \mathrm{~kg}$ and measuring $160 \mathrm{~cm}$ in length). The face, hands and legs were oedematous. Bilateral pale yellow pleural effusions were present measuring $350 \mathrm{ml}$ and $100 \mathrm{ml}$. The right and left lungs weighed $480 \mathrm{~g}$ and $360 \mathrm{~g}$ respectively; both showed basal collapse and minimal oedema. The state of the genital organs was consistent with the post-partum state. The 


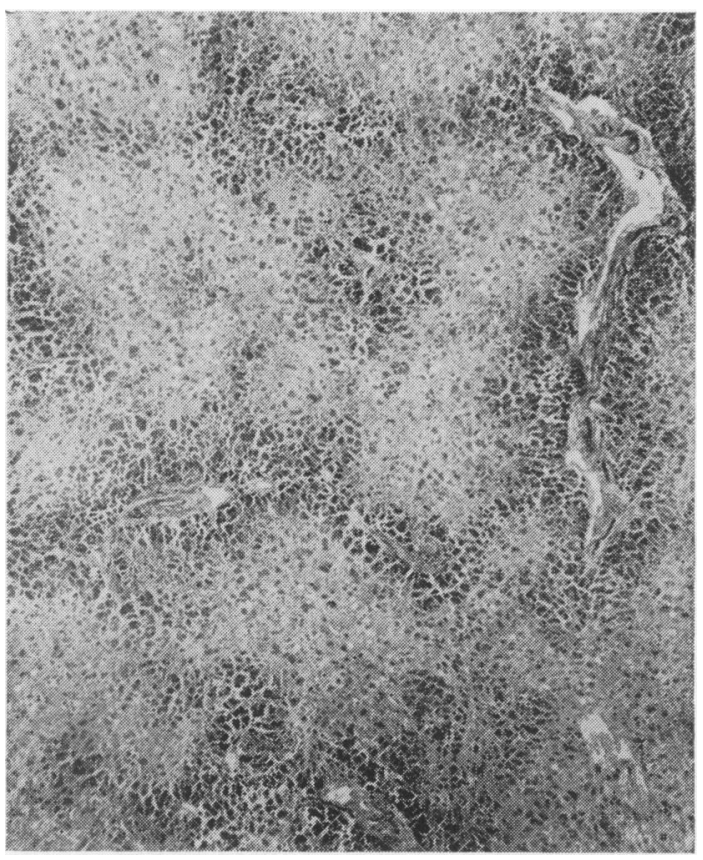

FIG. 1. Section of liver showing massive centrilobular and midzonal fatty change and necrosis. Haematoxylin and eosin $\times 29.5$.

liver was smaller than normal, weighing 1,068 $\mathrm{g}$ and the capsule was slightly wrinkled. On section, the parenchyma was firm and diffusely yellow. The gall bladder was normal and there was no evidence of extrahepatic biliary obstruction. Other viscera were macroscopically normal.

The most striking feature in sections of the liver stained with haematoxylin and eosin was the presence of extensive liver cell necrosis with sparing of the periportal zones (Fig.1). In the necrotic zones many of the hepatic cell outlines were preserved, revealing that some cells were swollen and vacuolated while others were shrunken and eosinophilic (Figs. 2 and 3). The nuclei were faintly staining in the former cells and an Oil Red $O$ fat stain confirmed the presence of lipid in their cytoplasm. The Gordon and Sweet reticulin stain confirmed collapse with condensation of the supporting connective tissue fibres in the necrotic areas. There were a number of intracanalicular bile plugs in the midzonal and centrilobular areas. Inflammatory cellular infiltrate was extremely sparse and consisted of a few lymphocytes and plasma cells seen mainly in the necrotic areas. In the periportal zone of normal looking liver cells, there was early regeneration in the form of ductular cell proliferation (Fig. 4). The glomeruli of the kidneys showed minimal basement membrane thickening consistent with the changes described in toxaemia of pregnancy. The bone marrow was hypercellular with a degree of erythroid hyperplasia and megakaryocytes were present in normal numbers.

The most prominent feature in the brain was the presence of many protoplasmic astrocytes throughout the grey and white matter. These astrocytes were of the Alzheimer II variety and only their large round or oval vesicular nuclei with a loose chromatin pattern could be seen. A periodic acid Schiff (PAS) stain demonstrated the presence of multiple small PAS-positive inclusions within the nuclei of these cells. Although present in all parts of the brain, these protoplasmic astrocytes were most numerous in the region of the subthalamic nucleus, the putamen, Ammon's horn, and the dentate nucleus. There were also degenerative changes in the neurons, involving particularly those of Sommer's sector in Ammon's horn and also those of the deeper layers of the cortical grey matter. The neuronal changes consisted of shrinkage and cytoplasmic eosinophilia, changes suggestive of anoxic encephalopathy. The Purkinjie cells of the cerebellum were well preserved and there was only a mild proliferation of Bergmann's layer of astrocytes in the cerebellum.

Attempts to isolate virus from postmortem specimens of liver and kidney were unsuccessful.

\section{DISCUSSION}

The diagnosis of acute fatty liver of pregnancy in this patient is based on clinical and pathological findings. The clinical picture of a rapidly progressive parenchymal failure accompanied by manifestations of toxaemia in the last month of pregnancy in a primipara is characteristic of the disease. The laboratory findings are also typical: hyperbilirubinaemia with an increase in serum alkaline phosphatase but no increase in $\gamma$-globulin and negative flocculation tests. Azotaemia is present in about half the cases and is generally ascribed to oligaemia. The terminal decrease in plasma urea is also a usual finding and is probably the result of decreased hepatic synthesis of urea. The intense leucocytosis is also common, recorded figures varying from 19,200 to 32,000 per cubic millimetre (Haemmerli, 1966). However, a haemolytic anaemia of the degree seen in this patient is unusual and does not appear to have been recorded previously. Its explanation is unknown.

The pathological findings in the present case are also unusual. The diagnosis of acute fatty liver of pregnancy is supported by the diffuse cytoplasmic fatty change in hepatocytes, the rim of normal cells adjacent to portal tracts, and the minimal inflammatory infiltrate in the liver. The massive midzonal necrosis seen here has not, however, been reported previously, and its explanation is uncertain. The patient received no hepatotoxic drugs before the onset of her illness, and there was no known exposure to hepatitis A virus. Lesions such as those produced by tetracycline toxicity are thus excluded. It may reflect the relatively long survival period of seven days after delivery, which is the longest re- 


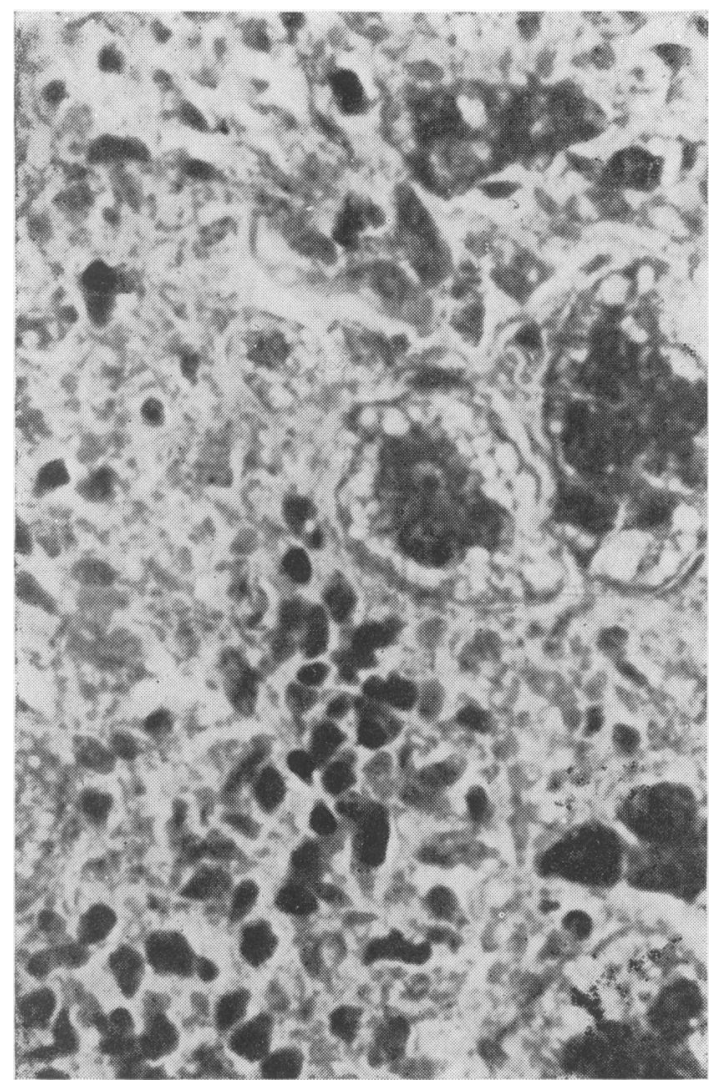

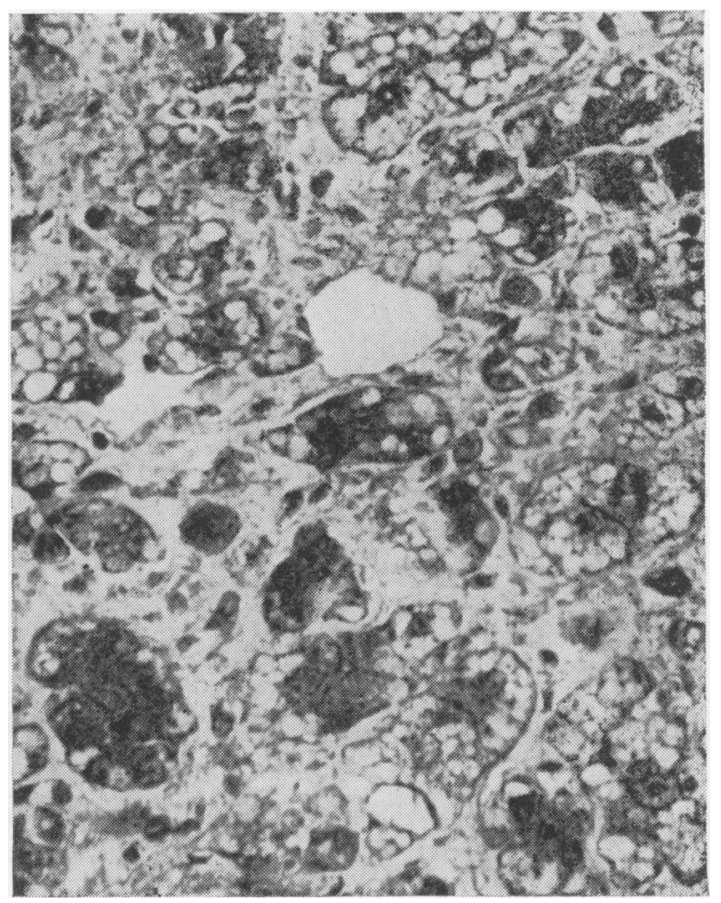

FIG. 3 .

FIG. 2 .

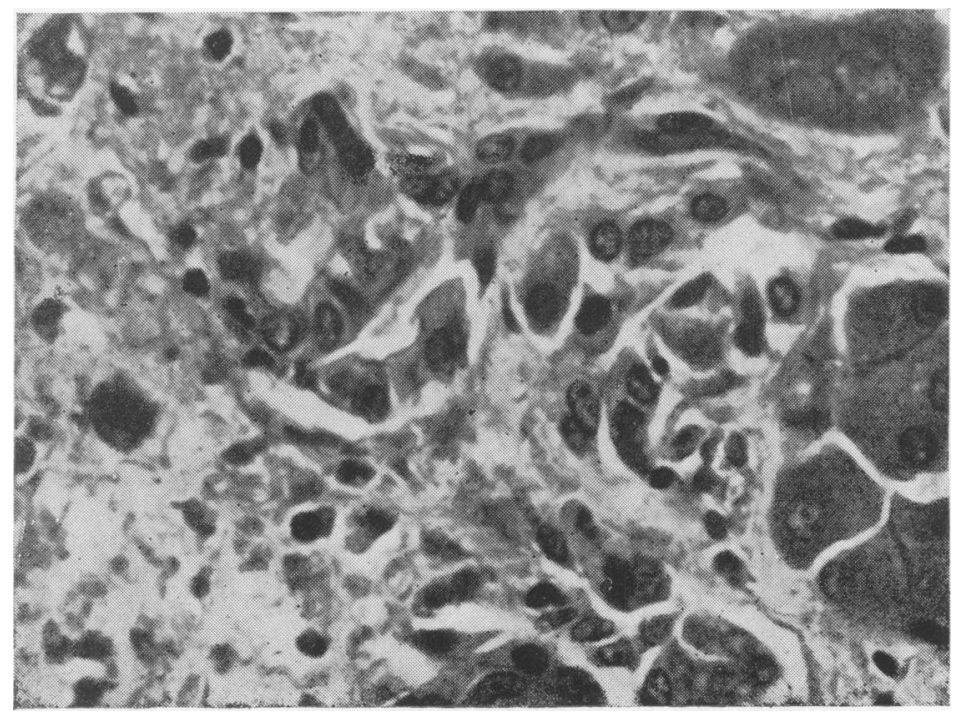

FIG. 4.
FIG. 2. Section of liver. Some of the hepatocytes are shrunken with densely staining eosinophilic cytoplasm, whilst others are swollen with a vacuolated cytoplasm. Oil Red $O$ confirms the lipid nature of the vacuoles. A few lymphocytes are present. Haematoxylin and eosin $\times 475$.

FIG. 3. Section of liver. The hepatocytes in the centrilobular zone contain many small cytoplasmic vacuoles. Haematoxylin and eosin $\times 475$.

FIG. 4. Section of liver showing surviving hepatocytes in the periportal region and early regeneration. Haematoxylin and eosin $\times 475$. 
corded (Moore, 1966), in which case it represents a more advanced stage of the disease than has previously been reported.

The case offers no further information as to the aetiology of acute fatty liver of pregnancy. The hepatic lesions are not specific, occurring also in tetracycline toxicity (Kunelis et al, 1965) and the recently described syndrome of encephalopathy and degeneration of the viscera in children (Reye, Morgan, and Baral, 1963). Isolations of reo- and coxsackie virus have been reported in this latter case, but were unsuccessful in the present case. The histological appearances in the liver also differ from those we have found in human hepatitis due to reovirus (Joske, Keall, Leak, Stanley, and Walters, 1964). The most probable explanation must be that fatty liver of pregnancy is related to the toxaemias of pregnancy, but is of unknown aetiology. The frequency of toxaemic manifestations in acute fatty liver of pregnancy would support this theory.

The final point worthy of mention is that the infant survived, making only the sixth surviving child in acute fatty liver of pregnancy. Haemmerli (1966) considers caesarian section indicated because the only two reported survivals of both mother and child followed caesarian section. One child survived when the disease developed after a normal delivery, and three children after spontaneous delivery soon after the onset of symptoms. In all these latter cases the mother died.

\section{SUMMARY}

A further case of acute fatty liver of pregnancy is reported, making the 41 st acceptable case in the literature. Unusual features were steady progression of the disease after natural delivery of a living child, severe haemolytic anaemia, and the finding at necropsy of massive midzonal hepatic necrosis.

We wish to thank Drs J. B. Blackwell and B. A. Kakulas for their assistance with the examination of the pathological material. Mr B. Brown prepared the photomicrographs.

\section{REFERENCES}

Haemmerli, U. P. (1966). Jaundice during pregnancy. With special emphasis on recurrent jaundice during pregnancy and its differential diagnosis. Acta med. scand., suppl. 444.

Joske, R. A., Keall, D. D., Leak, P. J., Stanley, N. F., and Walters M. N. I. (1964). Hepatitis-encephalitis in humans with reovirus infection. Arch. intern. Med., 113, 811-816.

Klatskin, G. (1963). Toxic and drug-induced hepatitis. In Diseases of the Liver, edited by L. Schiff, 2nd ed., pp. 453-538. Lippincott, Philadelphia. Pitman, London.

Kunelis, C. T., Peters, J. L., and Edmondson, H. A. (1965). Fatty liver of pregnancy and its relationship to tetracyline therapy. Amer. J. Med., 38, 359-377.

Moore, H. C. (1956). Acute fatty liver of pregnancy. J. Obstet. Gynaec. Brit. Emp., 63, 189-198.

Ober, W. B., and LeCompte, P. M. (1955). Acute fatty metamorphosis of the liver associated with pregnancy. A distinctive lesion. Amer. J. Med., 19, 743-758.

Reye, R. D. K., Morgan, G., and Baral, J. (1963). Encephalopathy and fatty degeneration of the viscera. A disease entity in childhood. Lancet, 2, 749-752.

Saint, E. G., and Joske, R. A. (1953). A note on fatty change in the liver complicating aureomycin therapy. Med. J. Aust., 1, 222-224.

Sheehan, H. L. (1939). The pathology of hyperemesis and vomiting of late pregnancy. J. Obstet. Gynaec. Brit. Emp., 46, 685-699. 1940). The pathology of acute yellow atrophy and delayed chloroform poisoning. Ibid., 47, 49-62.

Whitacre, F. E., and Fang, L. Y. (1942). Fatty degeneration of the liver in pregnancy. Report of a case with recovery: chemical and histologic studies. J. Amer. med. Ass., 118, 1358-1364. 